\title{
Pitfalls in the histological diagnosis of total colonic aganglionosis on appendicectomy specimens
}

\author{
Radhika Krishna O H', Srinivas Srirampur ${ }^{2}$, Vani Padmaja G J33, Ramesh Reddy Kota ${ }^{4}$ \\ ${ }^{1}$ Associate Professor, Department of Pathology, Osmania Medical College, ${ }^{2}$ Associate Professor, Department of \\ Pediatric Surgery, Gandhi Medical College, ${ }^{3}$ Professor, Department of Pathology, Niloufer Hospital, Osmania Medical \\ College, ${ }^{4}$ Professor, Department of Pediatric Surgery, Niloufer Institute of Pediatrics, Hyderabad, Telangana, India
}

Background: Hirschsprung's disease is the most important cause of functional intestinal obstruction in children. It is characterized by the absence of ganglion cells in the submucosal and myenteric plexuses on histology. In $10 \%$ of Hirschsprungs disease patients, involvement of the entire colon is seen in a condition called total colonic aganglionosis (TCA). The absence of ganglion cells in the appendix on histology has been considered diagnostic of TCA. The validity of this histological finding being taken as criteria for diagnosis is not clear. Aims and Objectives: This study examines the presence and the number of myenteric and submucosal ganglion cells in the appendices of suspected cases of TCA and compares these findings with controls, specimens of acute appendicitis, and histologically normal appendix in pediatric cases. Materials and Methods: Thirty-six appendix specimens of suspected TCA cases and controls, that is, ten each of acute appendicitis and histologically normal appendix in pediatric age group were included in this study taken up in the pathology department of a tertiary pediatric referral hospital. The presence or absence and the number of ganglion cells in each specimen was semiquantitatively evaluated in a blinded manner. These findings were descriptively compared and analyzed. The difficulties faced by the pathologist in reporting the pediatric appendix specimens were also documented. Results: The cases and controls showed that aganglionosis and no significant difference were noted in the number of ganglion cells per high power field between the cases and controls. The reporting pathologists enumerated quite a few pitfalls and problems encountered by them in the process of interpreting ganglion cell status of pediatric, particularly neonatal appendicectomy specimens. Conclusion: Aganglionosis of the appendix on histology may not be an ideal tool for the diagnosis of TCA. Difficulties in histological characterization of ganglion cells, technical errors in tissue embedding and the presence aganglionic skip areas might cause errors in the interpretation of ganglion cell status of appendix specimens, particularly infants, and neonates.

Key words: Appendix; Histology; Total colonic aganglionosis

\section{INTRODUCTION}

Hirschsprung's disease (HD) presents as a distal intestinal obstruction due to congenital absence of intramural plexus of ganglion cells or aganglionosis of distal bowel. Intestinal aganglionosis occurs due to aberrant colonization of the

\section{Access this article online}

Website:

http://nepjol.info/index.php/AJMS DOI: 10.3126/ajms.v13i1.39556

E-ISSN: 2091-0576

P-ISSN: 2467-9100

Copyright (c) 2022 Asian Journal of Medical Sciences

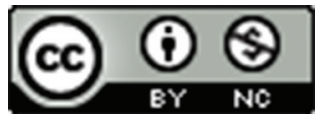

This work is licensed under a Creative Commons Attribution-NonCommercial 4.0 International License. 
accounting for $5-15 \%$ of the cases of HD. It occurs in about 1 in 50,000 live births. ${ }^{3-5}$

The appendix is frequently sampled for examining the myenteric ganglion cells in suspected cases of TCA. Evaluation of ganglion cells in the appendix as a guide to the diagnosis of TCA is very ambiguous. Despite the common understanding of the pathologists regarding the non-representativeness of the appendix in TCA, it is still submitted along with an ileal biopsy in suspected cases of TCA.

There is no clear opinion on the probability of a case being TCA if ganglion cells are absent. The appendix in a neonate is a minuscule structure with a poorly demarcated myenteric area. Tissue artifacts due to faulty embedding of the slender appendix, the presence of immature ganglion cells and neural tissue, and confusion in differentiating ganglion cells from other cells like lymphocytes present problems for pathologists reporting pediatric appendicectomy specimens.

Although appendicectomy is a safe and an easy procedure, there is no concurrence on its diagnostic role in TCA. This study attempts to elucidate the problems faced in the diagnosis of aganglionosis and subsequent TCA by sampling the appendix. Comparison of the ganglion cell status in appendices of suspected cases of TCA with cases of acute appendicitis and histologically normal appendices of pediatric controls will also be presented.

\section{Aims and objectives}

The aim of the study was to assess the ganglion cell status of appendices of suspected TCA cases, acute appendicitis and histologically normal appendix in pediatric age group and to enumerate the difficulties encountered in analyzing the ganglion cells on routine histology on pediatric appendix specimens.

\section{MATERIALS AND METHODS}

This study is a prospective observational study conducted in the pathology department of a tertiary pediatric referral hospital for a period of 4 years from June 2014 to June 2018.

A total of 36 appendicectomy specimens of suspected TCA cases along with ten appendix specimens of acute appendicitis and ten specimens of histologically normal appendix resected for other conditions such as congenital bands and malrotations in pediatric age group were included in this study.

All the formalin fixed appendix specimens were whole embedded as longitudinal and transverse sections. Serial sections were taken, stained with hematoxylin and eosin, and the submucosal and myenteric areas were studied in detail for ganglion cells. Two reporting pathologists blinded to the clinical details reported the slides and a final opinion was given in concurrence. A total of ten high power fields (HPF) were randomly selected for counting the ganglion cells. Care was taken not to repeat the same field twice. A total number of ganglion cells in ten HPF were counted and an average number of ganglion cells per HPF was calculated. Cases showing aganglionosis were documented in the cases and controls.

Simultaneously, all difficulties that were encountered in the reporting of the ganglion cells and hypertrophied nerve bundles in the appendix specimens were documented. The focal presence of ganglion cells, long skip zones, inconspicuous myenteric area, and crush artifacts were taken into consideration. Difficulties faced in identifying ganglion cells in the appendix, immature ganglion cells, confusion with other native cells of the appendix were also taken into account. Interesting findings were tabulated and analyzed.

\section{Statistical analysis}

Descriptive statistics were used in this study.

\section{RESULTS}

The study includes 36 appendix specimens of suspected TCA cases the age range of the patients was from 2 days to 14 months.

The ten controls of acute appendicitis and histologically normal appendix were taken in tandem from the pediatric appendix specimens received at the department of pathology.

The ages of the patients in suspected TCA cases were compared with the ganglion cell status of the appendix (Table 1).

Most cases suspected to be TCA (61\%) were in the age group of 1-10 days. Most of the aganglionic appendix

\begin{tabular}{|c|c|c|c|}
\hline Age & $\begin{array}{c}\text { Number of } \\
\text { cases }(\%) \\
n=36\end{array}$ & $\begin{array}{c}\text { Aganglionic } \\
(\%) \\
n=17\end{array}$ & $\begin{array}{c}\text { Ganglionic (\%) } \\
n=19\end{array}$ \\
\hline $0-10$ days & $22(61.1)$ & $15(68.1)$ & $7(37.8)$ \\
\hline $10-30$ days & $7(19.4)$ & $1(14.2)$ & $6(85.7)$ \\
\hline $1-12$ months & $6(16)$ & 1 (16.6) & $5(83.3)$ \\
\hline$>12$ months & $1(2.7)$ & 0 & $1(100)$ \\
\hline
\end{tabular}


specimens were also seen in these group in 15 out of 22 cases or $68.1 \%$.

We compared the ganglion cell status of the cases and controls. Suspected cases with the presence of ganglion cells in the appendix were lower in suspected TCA cases as compared to controls $90 \%$ and $80 \%$ in appendicitis and normal appendix, respectively (Table 2).

Ganglion cells could not be identified even after careful search in a small percentage of controls, $10 \%$ of appendicitis and $20 \%$ of normal appendix, respectively.

On semiquantitative estimation of average number of ganglion cells per HPF as detailed in the methodology previously, we found no significant difference in the average number of ganglion cells in the appendices of the cases and controls, an average of 3 to 3.3 ganglion cells per HPF was seen in the cases and controls though the range varied. 3.3 was seen in the normal appendix and 3.0 in appendicitis and suspected TCA (Table 3).

Cases showing clear the presence of ganglion cells in the submucosal and myenteric plexus were easy to diagnose. Difficulties were encountered by the reporting pathologists in the appendix specimens of neonates. The inconspicuous and thin muscularis propria and immaturity of ganglion cells posed difficulties in diagnosis (Figure 1). Confusion in differentiating immature ganglion cells from lymphocytes, endothelial cells, and stromal cells was also a problem in these specimens. Irregular distribution of ganglion cells

\begin{tabular}{lcc}
\multicolumn{3}{l}{ Table 2: Comparison of ganglion cell status of } \\
appendix specimens of cases with controls
\end{tabular}

$\begin{aligned} & \text { Table 3: Comparison of the average number of } \\
& \text { ganglion cells per HPF in the appendix in cases } \\
& \text { and controls }\end{aligned}$
\begin{tabular}{lcc} 
Group & $\begin{array}{c}\text { Range of ganglion } \\
\text { cells/HPF }\end{array}$ & $\begin{array}{c}\text { Average no of } \\
\text { ganglion cells/HPF }\end{array}$ \\
\hline $\begin{array}{l}\text { TCA } \\
n=36\end{array}$ & $0-10$ & 3.02 \\
$\begin{array}{l}\text { Appendicitis } \\
n=10\end{array}$ & $0-6$ & 3.04 \\
$\begin{array}{l}\text { Normal appendix } \\
n=10\end{array}$ & $0-8$ & 3.36 \\
\hline HPF: High power field, TCA: Total colonic aganglionosis
\end{tabular}

and large skip zones of aganglionosis was noted both in the cases and controls (Figure 2). The merger of ganglion cells into the circular and longitudinal muscle was also noted due to the small size and thin nature of the tissue and improper embedding.

Hypertrophied nerve bundles were also difficult to find in the aganglionic appendices of neonates. Immunohistochemistry with calretinin was useful in cases where it was difficult to characterize ganglion cells on hematoxylin and eosin stained sections.

\section{DISCUSSION}

Opinion about the reliability of the appendix in the diagnosis of TCA is controversial. Different points of view have been expressed in research papers of the past. While some researchers felt that the appendix was an unreliable tool in the diagnosis of TCA, ${ }^{6-9}$ others concluded that the appendix was indeed useful in the diagnosis of TCA. ${ }^{10-13}$

Diagnosis of TCA is challenging. Radiological findings are never conclusive. ${ }^{14,15}$ The diagnostic modality would be to demonstrate the aganglionic status of the entire colon by serial seromuscular biopsies. Based on the fact that the appendix which is an out pouching of the caecum and is located in the proximal part of the colon and based on the craniocaudal migration theory of

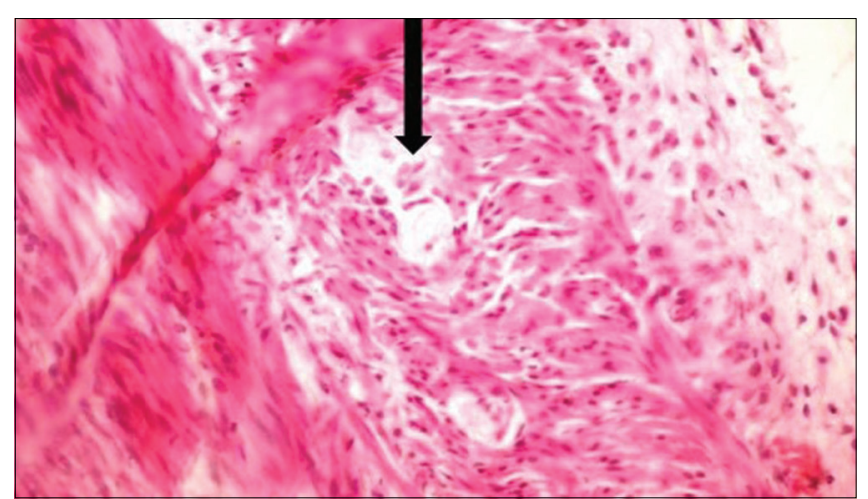

Figure 1: $\mathrm{H} \& \mathrm{E}(\times 40)$ - Immature ganglion cells in the myenteric plexus in a neonate (Arrow)

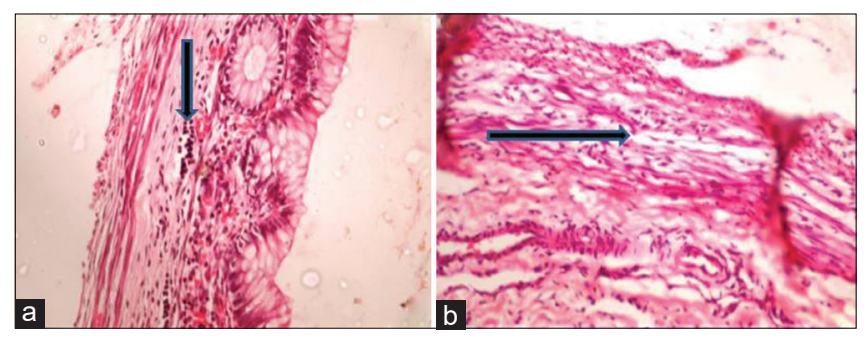

Figure 2: H\&E $(\times 40)$ - Suspected TCA case showing ganglionic (a) and aganglionic areas (b) in the same appendix (Arrows) 
neural crest cells it has been assumed that the absence of ganglion cells in the appendix represents aganglionosis of the entire colon.

In our study, we took up prospective histopathological analysis of appendix specimens to understand the pitfalls in this approach of using aganglionosis of the appendix to diagnose TCA.

The age of the cases that were suspected to have TCA was 2 days to 14 months; the majority of the cases were in the age group of $0-10$ days. Nearly $80 \%$ of patients with aganglionic appendix were neonates, 16 out of 17 aganglionic appendix specimens belonged to neonatal cases. Only a single case of the aganglionic appendix was seen in an older baby. On comparison of ganglion cell status of cases suspected as TCA with controls, that is, acute appendicitis and histologically normal appendix $47.2 \%$ of suspected TCA cases were aganglionic while $52.7 \%$ showed the presence of ganglion cells. About $100 \%$ of TCA suspected cases were aganglionic in a previous study. ${ }^{11}$ Other studies ${ }^{7}$ also found a $100 \%$ concurrence of aganglionosis and TCA. Interestingly $10 \%$ of acute appendicitis and $20 \%$ incidental appendicectomy cases were also aganglionic. In acute appendicitis dense inflammatory infiltrate obscured the ganglion cells and also appendix specimens of infants there were difficulties in identifying ganglion cells in myenteric areas of the appendix. Long skip zones and aganglionic areas were identified in both cases and controls. Shih et al., ${ }^{16}$ in 1998 described a case of a newborn infant who presented with acute perforation of the distal ileum. At laparotomy, the appendix was sent for histopathological analysis and was found to be aganglionic and an ileostomy was fashioned. Seven months later, at re-exploration ascending, transverse, and sigmoid colon biopsies were histologically analyzed and revealed the presence of normal ganglion cells. ${ }^{16}$ This was a surprise finding of an aganglionic appendix in a normally innervated intestine. They offered various explanations for this. The first explanation is a misinterpretation of the histological sample, which is very much possible as we saw aganglionic appendices in appendicitis cases $(10 \%)$. The presence of an ileal perforation may cause significant extrinsic inflammation of the appendix, which the authors felt could have affected the histological analysis of the appendix, and finally presence of skip zones might have caused erroneous reporting. We too in our study saw many such appendix specimens with large skip areas and this was identified easily as we whole embedded the specimens.

The presence of even a single ganglion cell rules out HD. We however undertook a semi quantitative analysis of ganglion cell numbers in the cases and controls. Although the range of the number of ganglion cells per HPF was variable, the average number of ganglion cells per HPF was comparable between cases and controls; an average of three ganglion cells per HPF was seen in cases and controls. This was another interesting finding in our study against the use of ganglion cells in the appendix as a diagnostic tool for TCA. A published a paper on neural hypertrophy in appendicitis and concluded that acute appendicitis cases had more ganglion cells in the submucosal and myenteric plexuses in comparison to controls, which is in contrast to our findings. ${ }^{17}$ Our study had pediatric subjects, predominantly infants among the cases and controls while their study was mostly in adults, Studies also found altered ganglion cells in acute appendicitis. ${ }^{18}$ The inflammatory process is said to have a negative effect on enteric ganglion cells and cause a decrease in their number. ${ }^{7}$ We found aganglionosis in both the cases and controls and also a nearly equal average number of ganglion cells per HPF in cases and controls. Skip zones or aganglionic areas were common to both. We conclude that histopathology of appendix has a low predictive value in TCA.

The two pathologists who performed the ganglion cell analysis and count have good experience in reporting HD cases. They opined that reporting of ganglion cells in appendix specimens posed many diagnostic difficulties. They felt that reporting full-thickness intestinal biopsies presented lesser problems than the appendices in children particularly newborns. Other opinions expressed were, submucosal area presented more problems in the identification of ganglion cells in comparison to the myenteric area. Ganglion cell distribution in the appendix was found to be irregular and seen merging into the circular and longitudinal muscle layers. Overlapping of the tissue during section cutting and embedding of both cases and controls was seen. Immature ganglion cells of the neonates also presented with difficulty in identification. They appeared small with dark nuclei and indistinct nucleoli. Furthermore, other cells such as lymphocytes, stromal cells, fibroblasts, and endothelial cells gave rise to confusion with immature ganglion cells. Hypertrophied nerve bundles were also difficult to identify in aganglionic appendices as the muscle layers are thin and the nerve population is immature. Hypoganglionosis or immature ganglion cells in neonates cause sparse neurons which may not be included in serial sections. ${ }^{16,19}$

Skip segments or zonal aganglionosis are increasingly recognized in HD. Isolated diagnosis of TCA based on the innervation of the appendix may not be accurate. The ENS is the largest and most complex division of the peripheral nervous system. The ENS, in common with the majority of extra-enteric peripheral ganglia, is formed from migration 
from the neural crest. ${ }^{20,21}$ In 1980, Allan and Newgreen ${ }^{22}$ isolated bowel segments from embryos at various stages of development, grew them on the chorioallantoic membrane, and found that enteric neurons appeared in a craniocaudal sequence, showing a vagal source. One explanation for the skip areas is that that these skip segments of the ganglionic intestine are derived from neuroblasts which when migrating in a craniocaudal direction during neural crest migration, cross the mesenteric border to a more distal part of the intestine and as a result end up well ahead of the wave front, colonizing an area within the aganglionic segment. This theory is based on studies of murine alleles that cause hereditary aganglionosis. Observations suggest that in addition to the anticipated intramural rostral caudal migration of the vagal neural crest cells in the large intestine, there is also extramural migration of neuroblasts taking place, along the mesentery, and into the colon.

The use of appendix as a diagnostic tool in TCA was first questioned by Kamoshita and Landing in 1968. ${ }^{9}$ His study found it difficult to identify myenteric plexus in the appendix and stated that the "size of the nerve population is proportional to the amount of muscle to be innervated" and therefore the value of appendicectomy in the diagnosis of neurological disorders is limited. ${ }^{9}$ A study of ganglion cells in guinea pigs revealed the least number of ganglion cells in the caecum. ${ }^{23}$ Same could be also the case in the human intestine though no such research was available at that time. ${ }^{9}$ Human appendix has a distinct neural network and the appendix may not be representative of the adjacent ileum and colon. ${ }^{24}$ Other studies also found the appendix unsuitable for commenting on ganglion cells and should not be taken as a reliable marker for determining the proximal biopsies. ${ }^{6,18}$ Aganglionic appendix with ganglionic colon has also been reported by some studies. ${ }^{11,12}$ Many authors felt that appendicular aganglionosis is not equivalent to TCA. ${ }^{25}$ The murine and avian experimental models suggest several pathways for ganglion cell migration that do not involve the appendix. ${ }^{26}$

To make the histopathological approach standardized guidelines were given by international working groups in certain gastrointestinal diseases including HD. ${ }^{27}$ These guidelines mention that appendix cannot be used for diagnosis of HD and serial colonic biopsies should be performed for the diagnosis of TCA. The appendicular biopsy is therefore unreliable for leveling of aganglionosis in TCA. Knowles and Digiorgio in their review articles agreed to the concerns regarding the appendicular histology being useful in the heterogenous repertoire of systemic diseases affecting the gut. ${ }^{28,29}$

Our study used a multipronged approach to understand the limitations in the utility of appendix in histological identification of ganglion cells and infers that the routine histological examination of the appendix has a poor predictive value in the diagnosis of aganglionosis and TCA.

\section{Limitations of the study}

This study is limited by the small sample size due to which statistical significance could not be calculated.

\section{CONCLUSION}

The ganglion cells in pediatric, predominantly neonatal vermiform appendices of suspected TCA cases, acute appendicitis, and histologically normal appendix were analyzed semi quantitatively and no significant differences were found in the number of ganglion cells in cases and controls. Aganglionosis was seen in both, to a lesser extent in controls as compared to cases. The reporting pathologists enlisted numerous diagnostic difficulties in the interpretation of ganglion cell status of pediatric and neonatal appendices. Aganglionosis of the appendix should not be used as an isolated diagnostic tool in TCA.

\section{REFERENCES}

1. Okamoto $E$ and Ueda T. Embryogenesis of intramural ganglia of the gutand its relationship to Hirschsprung's disease. J Pediatr Surg. 1967;2:437-443. https://doi.org/10.1016/s0022-3468(67)80085-x

2. Meijers $\mathrm{JH}$, van der Sanden MP, Tibboel D, van der Kamp AW, Luider TM and Molenaar JC. Colonization characteristics of enteric neural crest cells: Embryological aspects of Hirschsprung's disease. J Pediatr Surg. 1992;27(7):811-814. https://doi.org/10.1016/0022-3468(92)90371-d

3. Ikeda K and Goto S. Diagnosis and treatment of Hirschsprung's disease in Japan. Ann Surg. 1984;199(4):400-405.

4. Jordan F, Coran A and Wesley J. Modified endorectal procedure for management of long-segment aganglionosis. Ann Surg. 1981;194(1):70-74.

https://doi.org/10.1097/00000658-198107000-00012

5. Dykes E and Guiney E. Total colonic aganglionosis. J Pediatr Gastroenterol Nutr. 1989;8(1):129-132.

6. Lane VA, Levitt MA, Baker P, Minneci $P$ and Deans K. The appendix and aganglionosis. A note of caution-how the histology can mislead the surgeon in total colonic Hirschsprung disease. Eur J Pediatr Surg Rep. 2015;3(1):3-6.

https://doi.org/10.1055/s-0035-1552559

7. Phoonkaew T, Chiengkriwate P, Kun-Ngern S, Chowchuvech V, Patrapinyokul S and Sangkhathat S. Ganglion cells in vermiform appendix. Songkla Med J. 2007;25:425-429.

8. Mohanty S, Kini U, Das K, Puttegowda D and Yadav L. Appendicular biopsy in total colonic aganglionosis: A histologically challenging and inadvisable practice. Pediatr Dev Pathol. 2017;20(4):277-287. https://doi.org/10.1177/1093526617692913

9. Kamoshita $\mathrm{S}$ and Landing $\mathrm{BH}$. Distribution of lesions in myentericplexus and gastrointestinal mucosa in lipidosis and other neurologicdisorders in children. Am J Clin Pathol. 1968;49(3):312-318. 
10. O'Hare T, McDermott M, O'Sullivan M, Dicker P and Antao B. A retrospective cohort study of total colonic aganglionosis: Is the appendix a reliable diagnostic tool? J Neonatal Surg. 2016;5(4):44. https://doi.org/10.21699/jns.v5i4.460

11. N-Fekete $\mathrm{C}$, Ricour $\mathrm{C}$, Martelli $\mathrm{H}$, Jacob $\mathrm{SL}$ and Pellerin $\mathrm{D}$. Totalcolonic aganglionosis (with or without ileal involvement): A review of 27 cases. J Pediatr Surg. 1986;21(3):251-254. https://doi.org/10.1016/s0022-3468(86)80847-8

12. Anderson KD and Chandra R. Segmental aganglionosis of theappendix. J Pediatr Surg. 1986;21(10):852-854.

13. Shaw PA. The innervation and neuroendocrine cell population of the appendix in total colonic aganglionosis. Histopathology. 1990;17(2):117-121.

https://doi.org/10.1111/j.1365-2559.1990.tb00681.x

14. Newman B, Nussbaum A, Kirkpatrick JA Jr. and Colodny A. Appendiceal perforation, pneumoperitoneum, and Hirschsprung's disease. J Pediatr Surg. 1988;23(9):854-856. https://doi.org/10.1016/s0022-3468(88)80241-0

15. Arliss $\mathrm{J}$ and Holgersen LO. Neonatal appendiceal perforationand Hirschsprung's disease. J Pediatr Surg. 1990;25(6):694-695. https://doi.org/10.1016/0022-3468(90)90368-j

16. Shih TY, Chuang JH, Huang CC. Shih TY, Chuang JH and Huang CC. Aganglionosis of the appendix: Is it reliable for diagnosis of total colonic aganglionosis? J Pediatr Gastroenterol Nutr. 1998;27(3):353-354.

https://doi.org/10.1097/00005176-199809000-00017

17. Xiong S, Puri P, Nemeth L, O'Briain DS and Reen DJ. Neuronal hypertrophyin acute appendicitis. Arch Pathol Lab Med. 2000;124(10):1429-1433. https://doi.org/10.5858/2000-124-1429-nhiaa

18. Singh UR, Malhotra A and Bhatia A. Eosinophils, mast cells, nervesand ganglion cells in appendicitis. Indian J Surg. 2008;70(5):231-234.

https://doi.org/10.1007/s12262-008-0066-0

19. de Chadarevian JP, Slim M and Akel S. Double zonal aganglionosis in long segment Hirschsprung's disease with a "skip area" in transverse colon. J Pediatr Surg. 1982;17(2):195197.

https://doi.org/10.1016/s0022-3468(82)80213-3

20. Yntema CL and Hammond WS. The origin of intrinsic ganglia of trunk viscera from vagal neural crest in the chick embryo. J Comp Neurol. 1954;101(2):515-542.

https://doi.org/10.1002/cne.901010212

21. Yntema CL and Hammond WS. Experiments on the origin and development of the sacral autonomic nerves in the chick embryo. J Exp Zool. 1955;129:375-414. https://doi.org/10.1002/jez.1401290210

22. Allan IJ and Newgreen DF. The origin and differentiation ofenteric neurons of the ntestine of the fowl embryo. Am J Anat. 1980;157(2):137-154. https://doi.org/10.1002/aja.1001570203

23. Irwin DA. The anatomy of Auerbach's plexus. Am J Anat. 1931;49:141-166. https://doi.org/10.1002/aja.1000490106

24. Haney PJ. Zonal colonic aganglionosis. Pediatr Radiol. 1982;12(5):258-261. https://doi.org/10.1007/bf00971776

25. Sharp NE, Pettiford-Cunningham J, Shah SR, Thomas $P$, Juang D, St Peter SD, et al. The prevalence of Hirschsprung disease in premature infants after suction rectal biopsy. J Surg Res. 2013;184(1):374-377. https://doi.org/10.1016/j.jss.2013.03.088

26. Coe A, Avansino JR and Kapur RP. Distal rectal skip-segment Hirschsprung disease and the potential for false-negative diagnosis. Pediatr Dev Pathol. 2016;19(2):123-131. https://doi.org/10.2350/15-08-1686-oa.1

27. Laughlin DM, Friedmacher $F$ and Puri P. Total colonic aganglionosis: A systematic review and meta-analysis of longterm clinical outcome. Pediatr Surg Int. 2012;28(8):773-779. https://doi.org/10.1007/s00383-012-3117-3

28. Knowles $\mathrm{CH}$ and de Giorgio R. Observations on a vestigial organ: A potential surrogate for enteric neuromesenchymal disease. Neurogastroenterol Motil. 2008;20(4):263-268. https://doi.org/10.1111/j.1365-2982.2008.01090.x

29. Knowles $\mathrm{CH}$, de Giorgio R, Kapur RP, Bruder E, Farrugia G, Geboes K, et al. Gastrointestinal neuromuscular pathology: Guidelines for histological techniques and reporting on behalf of the Gastro 2009 international working group. Acta Neuropathol. 2009;118(2):271-301. https://doi.org/10.1007/s00401-009-0527-y

\section{Authors' Contributions:}

RKOH-Concept and design of the study, analysis, and interpretation of data, drafting of the article, literary review, revision, and preparation of manuscript;

SS- acquisition of data, analysis and interpretation of data, literary review, preparation of the manuscript, revision and final approval; VPGJ- Concept and design of the study, intellectual content; RRK- Concept, intellectual content, preparation of manuscript and revision.

\section{Work attributed to:}

Niloufer Hospital, Osmania Medical College, Hyderabad, Telangana, India.

\section{ORCID ID:}

Dr. Radhika Krishna O H- (1) https://orcid.org/0000-0001-6796-0143

Dr. Srinivas Srirampur- (iD https://orcid.org/0000-0003-1581-9679

Dr. Vani Padmaja G J- (1) https://orcid.org/0000-0002-6072-1382

Dr. Ramesh Reddy Kota- (1) https://orcid.org/0000-0002-2017-7546

Source of Funding: None, Conflicts of Interest: None. 